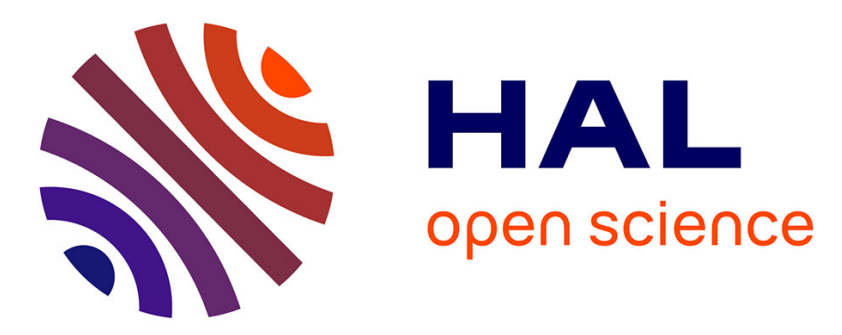

\title{
Forbidding Fixed Duration Contracts: Unfolding the Opposing Consequences with a Multi-Agent Model of the French Labor Market
}

Olivier Goudet, Jean-Daniel Kant, Gérard Ballot

\section{To cite this version:}

Olivier Goudet, Jean-Daniel Kant, Gérard Ballot. Forbidding Fixed Duration Contracts: Unfolding the Opposing Consequences with a Multi-Agent Model of the French Labor Market. Advances in Artificial Economics, 676, Springer, pp.151 - 167, 2015, Lecture Notes in Economics and Mathematical Systems, 978-3-319-09578-3. 10.1007/978-3-319-09578-3_13 . hal-01511130

\author{
HAL Id: hal-01511130 \\ https://hal.science/hal-01511130
}

Submitted on 20 Apr 2017

HAL is a multi-disciplinary open access archive for the deposit and dissemination of scientific research documents, whether they are published or not. The documents may come from teaching and research institutions in France or abroad, or from public or private research centers.
L'archive ouverte pluridisciplinaire HAL, est destinée au dépôt et à la diffusion de documents scientifiques de niveau recherche, publiés ou non, émanant des établissements d'enseignement et de recherche français ou étrangers, des laboratoires publics ou privés. 


\title{
Forbidding fixed duration contracts. Unfolding the opposing consequences with a multi-agent model of the French labor market
}

Olivier Goudet, Jean-Daniel Kant, and Gérard Ballot

\begin{abstract}
The model WorkSim is a new tool of analysis for the French labor market. The two main novelties of the model are that it simulates the gross flows of workers between different states (unemployment, employment, inactivity) on the basis of the rational decisions of individual heterogeneous agents, and that both firms and individuals are represented. the model is calibrated by an optimization algorithm, in order to reproduce the situation of the french labor market in 2011. In the present paper, we focus on experiments dealing with the suppression of the fixed duration contracts (FDC) and we unfold the opposing consequences of FDC on unemployment.
\end{abstract}

\section{Introduction}

The model WorkSim is a new tool of analysis for the French labor market. The first objective of the model is to reproduce the gross flows between six important states for the workers namely student, employment - distinguishing between fixed duration contracts (FDC) and open ended contracts (OEC), unemployment, inactivity, and retirement. The two main novelties of the model are that it simulates the gross flows of workers between the five states on the basis of the rational decisions of individual heterogeneous agents, and that both firms and individuals, the latter linked to households, are represented. Once calibrated by an optimization algorithm, in order to obtain a steady state situation for a large number of aggregate targets corresponding to 2011 data, the model is a tool for experimenting labor market policies,

Olivier Goudet · Jean-Daniel Kant

Sorbonne Universités, UPMC Univ Paris 06, UMR 7606, LIP6, F-75005, Paris, France

CNRS, UMR 7606, LIP6, F-75005, Paris, France

Gérard Ballot

CRED EA-7321, Université Paris 2

TEPP FR CNRS 3435 
including changes in the labor law. In the present paper, we focus on experiments dealing with the suppression of the FDC, which have an important place in the French labour market. Even though the FDC represent in 2011 only 10,1\% of the workers employed in the private sector against $84 \%$ for the OEC, $3.6 \%$ for the temporary help workers, and $2.2 \%$ for the apprentices, they count for $80 \%$ of the hires. Moreover the number of short FDC has increased steadily since 2003. The number of FDC of one week or less has increased by $120 \%$ over the period 2000-10, and the number of FDC between one week and one month has increased by $36 \%$ while the number of FDC of more than one month has remained almost stable with a 2,5\% increase [6]. The same source points to a decrease of the OEC of 6,6\%.The high and increasing turnover of the FDC is likely to have important effects on the workings of the labor market, and the unemployment experience of the workers who go through these FDC. There is presently a strong controversy about the effects of FDC on unemployment.

Buffer stock effect - Employers consider that they are a crucial necessity to respond to short term fluctuations of demand since the cost of firing workers on OEC is high (see for instance the study by C. de Froment [13]). Then the interdiction of FDC would, when an employer faces an uncertain demand, induce him to hire less than he would have if allowed to recruit on FDC, when demand rises, and steady state unemployment would be higher. The simple argument stating that higher firing costs lower employment in market with only FDC has however been questioned by several economists since high firing costs also lower dismissals, and the volatility of demand in this context of costly adjustment is another important determinant of employment. As Bentotlila and Bertola [4] have shown in an influential paper, the issue is complex, the net theoretical effect on steady-state unemployment is ambiguous, and simulations suggest that unemployment could be very little affected.

Screening effect - Other economists [14, 10, 7] have pointed out that FDC are used to screen young workers (with no firing cost) before giving an OEC to the most able ones.

Experience effect - Ballot has a somewhat different argument but in the same line [2,3]: the FDC offer some increase in experience which raises the probability to access an OEC, either in the same firm or also in another firm. ${ }^{1}$.

Stepping stone effect - The two last effects converge to say that if FDC did not exist, the firms would be reluctant to hire those of the inexperienced workers who do not have recognized diplomas, workers for whom they have little information on the productivity. The direct recruitment of these young workers would be lower, hence steady state unemployment higher. This convergent impact allows us to group the screening and the Experience effects under the common label of a stepping stone effect.

Churning effect - Other economists such as Blanchard and Landier point out that the termination of the FDC, given the interdiction to renew indefinitely (in France more than once such a contract), sends the workers to unemployment frequently [8]. The employers are assumed to be very reluctant to give an OEC to the

\footnotetext{
${ }^{1}$ For some empirical evidence see [9].
} 
workers at the end of the FDC, given the higher expected cost of OEC. This is called the churning phenomenon and it increases unemployment. Other motives for the use of FDC such as replacing ill workers exist also. No analytical model presently takes into account all these effects which go in opposite directions, for reasons of complexity, and economists presently do not know if the net effect of FDC on unemployment is positive or negative. Finally natural experiments are not available since no government has forbidden FDC, and there is no neat reverse experiment in which a government has suddenly allowed FDC ${ }^{2}$.

Our agent based model is able to include the role of FDC as a screening device with an experience effect, and it also takes account of the important flows out of FDC into unemployment (the churning effect). In a nutshell, The WorSim model is a two sided search model of the labor market, with individuals searching for a job, either as unemployed or on-the-job, if they are not satisfied with the total utility provided by the job, wage and conditions of work. They have a reservation utility. They may also give up searching since it has a disutility in terms of time, become inactive and rely on welfare or family income. Firms post vacant jobs with a wage, and set a minimum productivity for hiring a candidate. If candidates apply, the firm evaluates their productivity with a noise, and selects the best, or none if the best does not attain the minimum productivity. This modeling strategy leads to a search model with microfoundations which respect the heterogeneity intrinsic to the search approach to economics. It strongly differs with the matching models in the line of Mortensen-Pissarides [24] which assume the existence of an aggregate matching function. WorkSim therefore allows for non linearities in the hiring of competing heterogeneous workers, non linearities which are likely to be central in the workings of a labor market with two types of jobs. WorkSim has three additional features that make this model differ from matching models. Decisions are based on bounded rationality, there are keynesian features (downward rigidity of nominal wages of insiders, and a minimum wage, but new hires wages are influenced by the tension on the labor market), and lastly true productivity of a worker is learned by the employing firm over time but never perfectly known. Most of these features are essential to determine the gross flows, and do realistic policy experiments.

\section{Model outline}

In this section, we outline the main features of the WorkSim Model ${ }^{3}$. There are three types of agents in WorkSim : Individuals, Firms and a Public Sector that recruits employees, collects payroll taxes on businesses, and sets (exogenously) public policies for the Labor Market. In addition, the model uses three artifacts (in the sense of [25]) to deliver essential services to the agents :

\footnotetext{
${ }^{2}$ Boeri in his survey of the literature on employment protection does not mention such an experiment [27].

${ }^{3}$ A more detailed presentation of this version of WorkSim could be found in our reference paper here : [http://www-poleia.lip6.fr/解t/WS1.6_MCR.pdf]
} 
- JobAds, which receives job offers from the firms and job applications from the job seekers. Dissemination of information, however, is based on the job search process, according to the principles of the theory of search [26].

- a demographic module, which manages the demographic processes in the model (retirement, death ...).

- a "statistical institute" that calculates some statistics needed by the agents (e.g. tension in labor market), and disseminates information to a limited number of agents.

One distinctive feature of the WorkSim model is to integrate a fairly complete and flexible institutional framework that includes (1) the necessary elements of the French labor Law (including two types of contract : fixed duration contracts (FDC) and open ended contracts $(O E C)$, permanent layoffs and discharges, redundancy payments, ... ), and (2) government decisions (minimum wages, welfare benefits, ...).

The simulation cycle includes four main steps, as shown in Figure 1 below :

1. Firm decisions : manage contracts \& vacancies, evaluations, job creation / destruction;

2. Individual decisions : entering/leaving labor market, job search ;

3. Firm decisions : manage applications and promotions ;

4. Demography : household dynamics, retirements, aging.

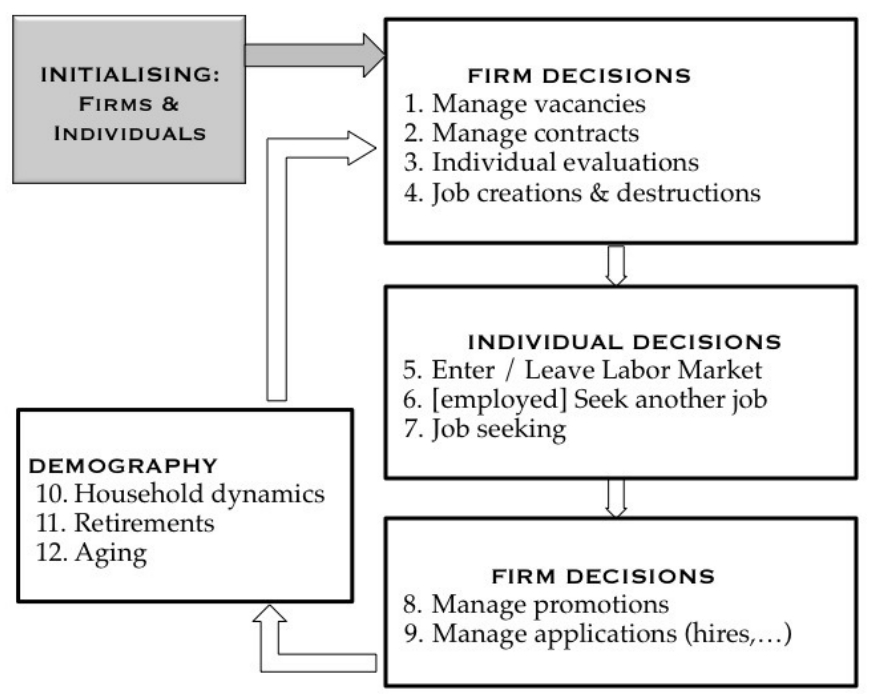

Fig. 1 The simulation cycle in WorkSim

The length of one period (i.e. one tick) in the simulation cycle corresponds to one week in the real world, in order to take into account very short term contracts (one 
week duration) that are found in the French labor market. Moreover, when statistics are needed, we took 2011 as a reference year, when we could find the most recent and complete statistical data and sources.

\subsection{Firm decisions}

In the current version of WorkSim, there is one good, and each employee produces a certain amount of a variety of this good which is unique to the firm but different from other firms variety only by the heterogeneous preferences of the consumers for this variety, and the fluctuations of these preferences (horizontal differentiation). The price is then unique and fixed. The only production factor is the labor, like in many agent-based model of labor market. Therefore, the firm production is linear additive in terms of hours of work, and some employees only work part-time.

Productivity and salary - Positions and employees are not identical in terms of productivity. There is a base productivity attached to each position, and the employee will modulate its value, through his general productive characteristics (core productivity and general human capital built from work experience ), and the specific human capital in the position he holds. Moreover, the employer has only a imperfect and evolving information on individual productivities. A hiring salary is also set for each potential position. It includes the minimum wage in France (SMIC), the base production modulated by the margin taken by the firm and the human capital of the employee.

Firm demand - At start, employees are randomly assigned to each company, which determines each global productions companies $Q_{j, t=0}$, with $j=1 . . N$ and $N$ is the total number of firms. We assume initially that the requested demand $D_{j, t=0}$ to one particular firm corresponds to the quantity produced plus an additional initial share representing a margin that will allow him to create his first job vacancies. The global demand for all the firms in our model at $t=0$ is $D_{t=0}^{\text {total }}=\sum_{j=1}^{N} D_{j, t=0}$. In our economy, the market share of the firm $\mathrm{j}$ at $t=0$ is given by $M S_{j, t=0}=\frac{D_{j, t=0}}{D_{t=0}^{\text {total }}}$. We assume that the distribution of this demand varies between firms. Therefore we apply a stochastic shock on the market share of each firm each period (random walk)

$$
\forall t, M S_{j, t}=M S_{j, t-1} \times\left(1+\mathscr{N}\left(0, \sigma_{M S}\right)\right)
$$

$\sigma_{M S}$ is an exogenous parameter.

Therefore the demand of the firm $\mathrm{j}$ is updated each period with this new market share :

$$
D_{j, t}=\frac{M S_{j, t}}{\sum_{k=1}^{N} M S_{k, t}} \times D_{t}^{\text {total }}
$$

Job creation - During job creation process, job characteristics depend firstly on the choice between FDC and OEC : this choice is made randomly according to the 
same probabilities for all firms, which differ depending on the qualification. Three levels of qualification are currently considered in WorkSim : employee or worker, middle level and executive. If a FDC is drawn, its duration will be determined again by drawing, according to qualification. Then, for the position to be definitively created, the firm estimates its expected profit and takes into account of :

- the expected productivity of the position estimated by prospection (with informations about several randomly drawn job seekers)

- the expected salary of the position with payroll taxes the firm has to pay for each employee

- the expected total cost of vacancy amortized over the expected duration of the contract (cost of publication of the post, time devoted to interviews by recruiters...). This cost is estimated by learning.

- the end cost of the contract : severance pay for FDC contract (10\% of the cumulated wage paid during the contract) or potential firing cost for OEC contract estimated by learning.

If the profit is positive, a vacancy is created and sent to a limited number of job seekers per period through JobAds.

Vacancy destruction - In case there is a significant reduction in its demand, the company plans to remove one or more vacancies. Moreover, the vacancies that are not filled in excess of a period of higher vacancy than a certain threshold are deleted.

Hiring - A two-step process, the process of sorting symmetrical positions by job seekers, takes place :

(a) Firstly the firm assigns a score to each candidate (internal or external), this score is the expected profit for the company in the event the candidate is hired ; then the best (highest profit) candidate is selected.

(b) Thereafter, the firm verifies that the candidate passes the hiring norm (computed by the firm as a profitability threshold, taking also the labor market tension into account). If this is the case, the candidate is hired; otherwise, the position remains vacant.

Employee management - Employee evaluation takes place at the end of the trial period for FDC and OEC ; at the end of FDC contract to decide if it should be renewed ; at the end of FDC contract, if the transformation of FDC to OEC is to be considered ; and every year, at the contract's anniversary date, for each FDC employee. In order to decide whether the employee should be kept, the firm calculates a profit for each scenario (to keep the employee or not). Moreover, at each period, each employee has a fixed probability to be automatically fired for a professional misconduct "observed" by the employer.

Economic firings - An evaluation of the financial viability of the company is done every month. The first date of the balance sheet is drawn randomly, then balances take place every month from this date. The company calculates annual profit 
made and monthly costs: if its ratio is below a certain threshold, the company has a loss and starts an economic firing process : (1) all vacancies are removed, and (2) the company fires "randomly" a number of employees on economic ground. This number is chosen as the minimum number of persons to fire in order to return above the profit threshold.

Firm bankruptcy - If a company has no employee anymore, it is considered bankrupt and disappears from the simulation. The manager becomes unemployed. However, we decide in our simulations to keep the number of firms constant. Hence, when a bankruptcy has occurred, we randomly select an active individual in the simulation who creates a new firm and sets in as a manager (in OEC) and a producer.

\subsection{Individual decisions}

The individuals take decisions at each period of the simulation. This decision process is modeled with a state machine, where one individual will be in one particular state : student, inactive, unemployed, employed not searching, employed searching a new job or retired. The transitions between these states can be caused by individual choices (for example : to start studying, to quit a job...), by external events (firing, death...), or eventually by a sequence of two decisions (applying for a job, and the firm hires the candidate). The decision-making process of individuals is sequential : he transition from one state to another is done by comparing the utility level of the current state with the expected utility level in a new state.

The utility functions have the generic form of a Cobb-Douglas function :

$$
U=(\text { Income }+ \text { Amenity }+ \text { Stability })^{1-\alpha}(\text { Free Time })^{\alpha}
$$

This utility function is a weighted aggregation of four factors :

Income : weekly income in euros (salary per week in employed state, unemployment benefit when in unemployment state, ...)

Amenity : non-monetary features perceived by the individual (social recognition, working environment, job hardness...), converted into a percentage of salary, and expressed in euros

Stability: criteria reflecting the preference of the individual for stability, i.e. for a job with the longest possible remaining contract duration. The maximum value is given for a permanent position (OEC) because its duration is - theoretically - indefinite. This stability is converted here into a percentage of salary and is expressed in euros.

Free time : free time per week available for the individual outside his working hours.

The parameter $\alpha \in[0,1]$ encodes the preference of the individual for leisure or work. 
Job search - The job search is model as a four steps process and only concern agents in unemployed state or employed and searching for a new job:

1. At start, the individual requests from JobAds a list of vacancies matching their qualifications and also some with an upper level of qualification.

2. He/she applies to the best offer he receives that exceeds his reservation utility

3 . If the job seeker does not receive bids vacancies that match their level of qualification or all of its applications are rejected, he/she lowers his reservation utility.

4. Employees (simply employed or on-the-job-search) whose seniority in the firm exceeds a threshold parameter apply automatically to internal offers whose qualification is strictly a notch above their own level.

\section{Model scaling method}

First of all, we scale the number of firms of the private sector (source INSEE [17]). The factor retained is $1 / 4700$ for the number of firms and individuals. With the total number of jobs obtained during this firms scaling, we adjust the initial number of "employed" individuals in the model. In total, we obtain 808 firms with 4411 individuals in these private firms. We add public servants in a proportion of $21.3 \%$ (source INSEE [22]) to this number of employees in the private sector. Next we include the numbers of "inactive", "unemployed", "retired" and "student" agents corresponding to 2011 statistics [20]. In the end we obtain 8713 individual agents and 808 firm agents, for a total of 9521 agents in the simulation.

\section{Model Calibration}

\subsection{Minimization of a fitness function}

To calibrate the model parameters (35) we minimize a fitness function which is the weighted sum or the relative spreads between the outputs of our model and real targets of the French labor market in 2011 (58 targets overall) regrouped in different categories :

- 7 targets on unemployment rate by age range and by qualification level (source INSEE [19])

- 6 targets on activity rate by age range and by gender (source INSEE [18])

- 21 targets on wages by age range and by qualification levels, and annual wages distribution per decile on the global population (source INSEE [21])

- 9 targets on labor flows (source DDMO/DARES [12])

- 9 targets on annual transition rate (source employment survey Enquête Emploi (Jauneau 2011) [23]).

- 3 targets on share of long term unemployment by age range (source INSEE [20]) 
- 3 additional targets on part-time job proportion in employment ([20]), vacancy rate (COE 2013 [11] and the ratio of employed "looking for a new job" in the simulation [16]

\subsection{Calibration method}

This fitness function is minimized at a horizon of 2600 periods (each period corresponds to one week, then 2600 periods correspond to 50 years in the reality). This choice of 50 years corresponds to a full career of the youngest agents and ensure that all agents have a fully simulated CV in the model and there is no bias related to the initialization phase of the model. To minimize our fitness function, we choose the evolutionary algorithms CMA-ES [15], which is one of the most powerful algorithm to solve this kind of problem [1]. Once the fitness function is minimized at the horizon of 2600 periods in a steady state, we save all the states of the agents. This backup files will be the starting point for our analyzes of model variants.

\subsection{Calibration results}

We obtain a median relative spread between the outputs of our model and the real targets of $16.5 \%$. These outputs are averaged over 240 simulations. All the targets and parameters values are given in our reference paper ${ }^{4}$.

\section{Suppression of Fixed Duration Contract (FDC)}

Once the model is calibrated, we aim to analyze the impact of a variant of labor policy in our model. In this paper, we test a Fixed Duration Contract (FDC) suppression. As in our model we only have two types of contract OEC and FDC (which is supposed to include all temporary contracts like interim and apprentice contract in our model), when we suppress FDC, only open-ended contracts (OEC) remain on the labor market.

We designed two simulation sets, one with OEC and FDC and one with OEC only. For each set, we depart from the backup file mentioned above (cf. 4.2) and run 240 simulations (each one having a four-year duration). The outputs presented in our results below are computed as averages of the last year over these 240 simulations.

\footnotetext{
${ }^{4}$ http://www-poleia.lip6.fr/ kant/WS1.6_MCR.pdf
} 


\subsection{Global impact by age group}

\begin{tabular}{|c|c|c|c|}
\hline & With FDC & Without FDC & Gross spread \\
\hline Global Unemployment rate & $9.5[9.426,9.574]^{*}$ & $2.60[2.52,2.67]^{*}$ & $-6.9^{* *}$ \\
\hline 15-24 Unemployment rate & $20.4[20.22,20.62]^{*}$ & $6.5[6.30,6.66]^{*}$ & $-13.9^{* *}$ \\
\hline 25-49 Unemployment rate & $7.9[7.82,7.96]^{*}$ & $1.6[1.50,1.61]^{*}$ & $-6.3^{* *}$ \\
\hline 50-65 Unemployment rate & $8.6[8.48,8.65]^{*}$ & $3.2[3.11,3.29]^{*}$ & $-5.4^{* *}$ \\
\hline Global Employment rate & $62.6[62.55,62.65]^{*}$ & $68.6[68.52,68.65]^{*}$ & $+6.0^{* *}$ \\
\hline 15-24 Employment rate & $31.5[31.36,31.56]^{*}$ & $37.9[37.73,37.99]^{*}$ & $+6.4^{* *}$ \\
\hline 25-49 Employment rate & $80.4[80.36,80.50]^{*}$ & $87.2[87.13,87.26]^{*}$ & $+6.8^{* *}$ \\
\hline 50-65 Employment rate & $55.9[55.83,56.00]^{*}$ & $61.1_{[60.32,60.48]^{*}}$ & $+5.2^{* *}$ \\
\hline
\end{tabular}

Employment rate : ratio of the employed over total population in the bracket $15-65 *$ Confidence interval at $95 \% * *$ significant at $1 \%$ threshold with Student test

Table 1 Global impact by age of FDC suppression after 4 years

As seen in Table 1, we observe a significant decrease of unemployment rate for all age groups when we suppress the fixed duration contracts in the labor market. This decrease is particularly true for young people, as they are were more concerned by these short-term contracts.

In our model, the preference for the stability criteria (i.e. preference for OEC over FDC) is taken into account by the individuals in their utility evaluation and decisionmaking process (cf. equation 3), but we observe the same significant decrease of unemployment rate in our simulation even if we the labor supply does not depend on the expected duration of the contract.

\subsection{Impact on employee turnover}

To characterize churning, we measure the degree of mobility of our individuals with the employee turnovers (given by the average of the entry and exit rates). The results are shown in Table 2 below.

With FDC the labor market is characterized by a high job turnover, especially among young people. When we suppress them, we observe a significant decrease of this job turnover, with less entry rate, but also less exit rate. This result suggests that the suppression of FDC reduces the global churning effect on the labor market. This reduction of mobility is much higher for the young (-59\% for the $15-24,-54 \%$ for the $25-49$ and $-23 \%$ for the seniors). When we suppress the FDC, the firm's screening effect obtained by short-term contracts remains, as more workers are fired at the end of the trial period. We also observe an increase of the number of layoffs for economic and personal reasons. These layoffs are used by firms to adjust their production in response to an idiosyncratic demand shock. 


\begin{tabular}{|l|c|c|c|c|c|c|c|c|}
\hline & \multicolumn{3}{|c|}{ With FDC } & \multicolumn{3}{c|}{ Without FDC } \\
\cline { 2 - 10 } & Global & $15-24$ & $25-49$ & $50-64$ & Global & $15-24$ & $25-49$ & $50-64$ \\
\hline \hline Turnover rate & 33.5 & 64.3 & 27.1 & 36.0 & 18.9 & 26.2 & 12.3 & 27.8 \\
\hline Entry in FDC rate & 24.5 & 56.8 & 20.7 & 20.4 & 0.0 & 0.0 & 0.0 & 0.0 \\
\hline Entry in OEC rate & 8.9 & 16.5 & 6.3 & 11.8 & 18.9 & 36.8 & 12.9 & 25.0 \\
\hline Exit rate & 33.6 & 55.3 & 27.2 & 39.8 & 18.0 & 15.7 & 11.6 & 30.6 \\
\hline end of trial period rate & 3.3 & 3.8 & 2.1 & 5.7 & 5.1 & 3.9 & 2.6 & 11.2 \\
\hline layoff for eco. reasons rate & 1.0 & 1.2 & 1.1 & 0.9 & 1.7 & 2.7 & 1.7 & 1.4 \\
\hline layoff for other reasons rate & 3.3 & 2.7 & 2.6 & 5.3 & 4.2 & 3.0 & 3.1 & 7.0 \\
\hline
\end{tabular}

Table 2 Impact of FDC suppression on turnover rates by age range

In the present version of the WorkSim Model the adjustment is not totally different between the case with FDC and the case without FDC. In the case with FDC, only the FDC which come to the end of their contract can be used for the adjustment, which therefore also relies on end of trial periods, personal and economic layoffs. In the case with only OEC, adjustment is also possible because layoffs of workers with a tenure less than one year do not receive severance costs, but firms handle only salary costs during the advance notice period, and therefore firing is not on average very costly.

To summarize, the two cases offer the possibility to firms to adjust, and FDC do not provide a much higher buffer stock effect which would lower the unemployment in comparison to the only OEC case. The adjustments of firm production with end of trial period and layoff result in a global decrease of OEC duration (from 286 to 188 weeks). We observe a clear increase of the proportion of really short Open Ended Contracts : the proportion of contract with an observed duration less than 1 month is multiplied by 2.4 and also by almost 1.4 for less than 6 months contracts. Hence, some precarity remains among the recently hired individuals, even though globally the exit rate is divided by 2 .

\subsection{Impact on flow diagrams of individuals}

To highlight this reduction of the churning effect, we present in this section the flow diagram $^{5}$ for all individuals with and without FDC.

In the diagram of all individuals with FDC (Figure 2), the labor market is characterized by high rates of rotation between the status of "unemployed" and "Employee

\footnotetext{
${ }^{5}$ Each type of flow is measured in two ways. The percentage in brackets indicates the proportion of agents of a group who change state. This is actually a probability of transition to a state per period for a given agent. These probabilities are very low because they are calculated on a weekly basis but they show perfectly the relative probabilities to change state. The numbers associated with the arrows indicate the average number of agents who move from one state to another each period. These numbers of agents are given with the full-scale numbers (number of agents in the simulation multiplied by the scaling factor of 4700) and are stated in thousands of agents. The thickness of the arrow in the diagram shows the "flows strength" compared to the other flows.
} 
in FDC". Entry rates in FDC are more than two times greater than the rate of direct entry in OEC. Exit to unemployment is also a major stream, the second in size. The conversions of FDC into OEC represent only $11.8 \%$ of the exits, the others persons go to unemployment. Therefore, an important part of agents alternate short periods of temporary work with periods of unemployment. Besides these "precarious" status, the majority of employees are employed in very stable OEC, even if some of these permanent employees are always looking for another more attractive job in OEC (transition to the "on the job search" state). When we suppress FDC (Figure 3), we observe an increase of the flow strength between Employment and Open-ended Contract. The important part of agents who alternated short periods of temporary work with periods of unemployment when FDC was available is partly replaced by agents who alternate unemployment and very short employment episode in OEC.

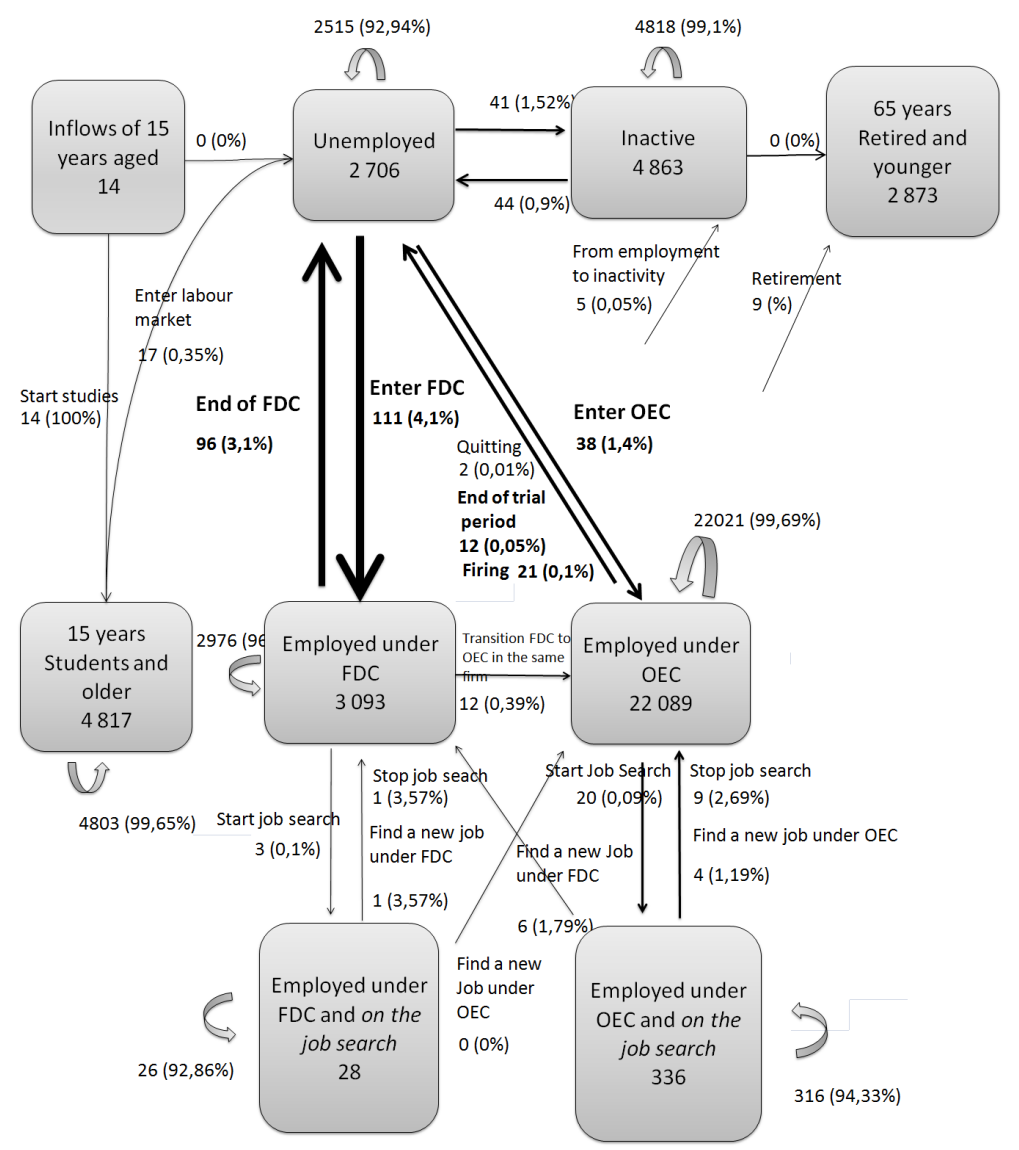

Fig. 2 Flow diagramm of individual with FDC (in thousands) 


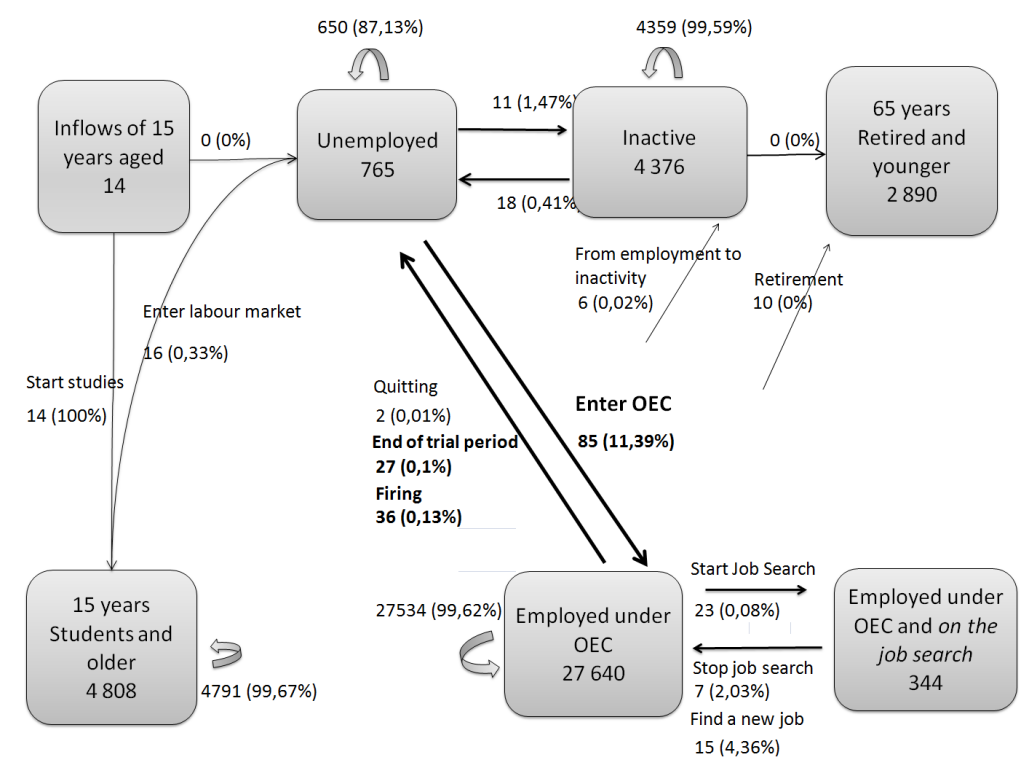

Fig. 3 Flow diagramm of individual without FDC (in thousands)

\subsection{Impact on the Beveridge curve}

This decrease of employee turnover results in less frictional unemployment. Indeed, with the suppression of very short term contract, the job turnover decreases and the mean duration of employment spell increases. Hence, we observe a net decrease of the number of firms searching for employees and of the number of unemployed searching for jobs per period. This explains the net shift of the Beveridge ${ }^{6}$ curve towards the origin when we suppress FDC, as shown in figure 4.

This observation is consistent with the results obtained by Bentolila and al. in 2010 [5] in their comparison of the labor market of France versus Spain. They show the large outward shift in the Beveridge curve of the Spanish labor market during the crisis in 2010, because this labor market was characterized by a strong duality between OEC and FDC and by a high share of individuals employed in FDC. This outward shift of both unemployment rate and vacancy rate is an indicator of frictional unemployment and reallocation distortions due to the churning effect.

\footnotetext{
${ }^{6}$ the Beveridge curve is obtained by shifting the global demand of our model from $50 \%$ to $200 \%$ of the base value.
} 


\section{Bedveridge Curves}

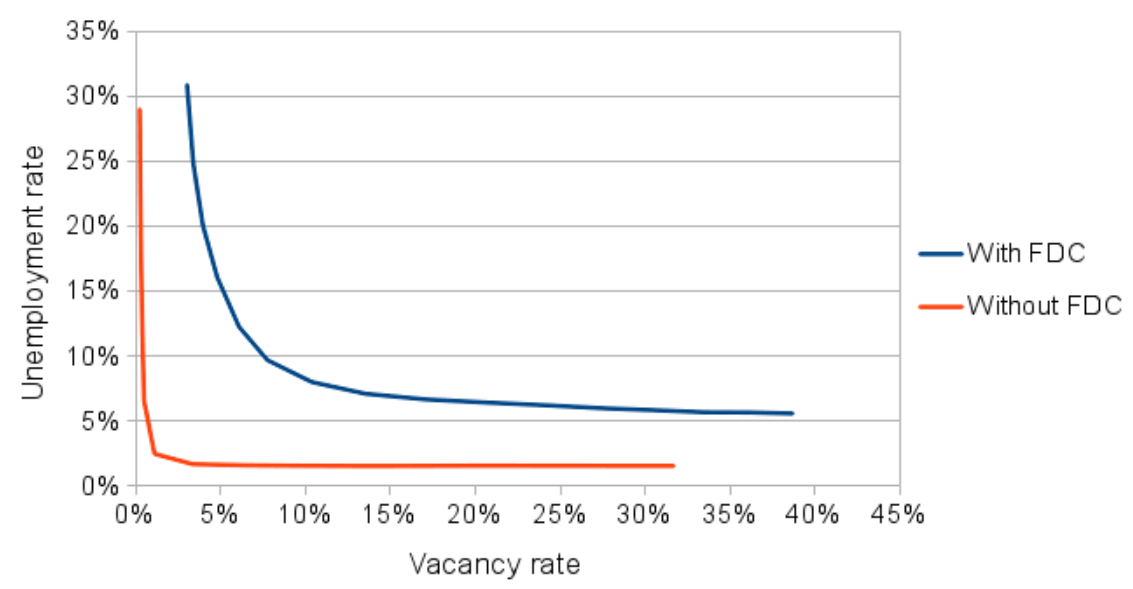

Fig. 4 Beveridge Curves with and without FDC

\subsection{Sensitivity of FDC suppression to the volatility of firms demand}

In our model, the dynamics of the firms demand has an impact on their decision process concerning jobs creation and destruction (cf. section 2.1). We aim to test in this section the sensitivity of our results to the volatility of firm demand. We run 48 simulations with FDC and 48 simulations without FDC with values of volatility of firms market share $\sigma_{M S}{ }^{7}$ each period between 0 and 0.07 (i.e. between $0 \%$ and $200 \%$ of the calibration value 0.035 ).

The more the volatility of firms demand increases, the more firms are likely to hire and fire employees each period in order to adjust their production level to their demand level. Figure 5-a on employee turnover shows two differences between the two cases. First employee turnover is always lower without FDC as we have seen in table 2. Second the rate of increase in turnover rate when volatility raises is higher with FDC, due to the higher flexibility of short term contracts. Figure 5-b shows that when the volatility is high, the unemployment rate for young people is high with FDC and low without FDC. This high volatility is the case of the base simulation (section 5). The high volatility associated with a high turnover then causes an important churning effect. When the volatility rate is very low, the hierarchy of unemployment rates for the young is reversed. The turnover rate is very low and it becomes very hard for the young people and more generally for the individual with little human capital to enter into employment, and this increases long term unemployment ( figure 5-c ). This difficulty is smaller when FDC are available since inexperienced worker and individual unemployed have a higher probability to get a

\footnotetext{
${ }^{7}$ As in equation 1 in section 2.1
} 
a) Employee Turnover rate

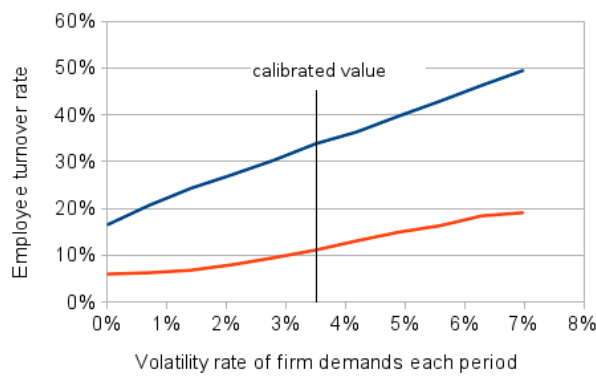

c) share of long term unemployment

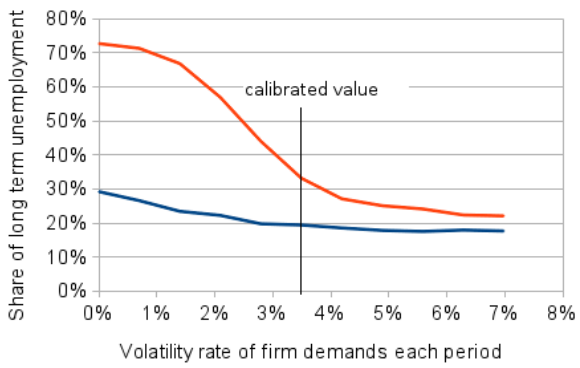

b) Unemployment rate for young people ( $<25$ years)

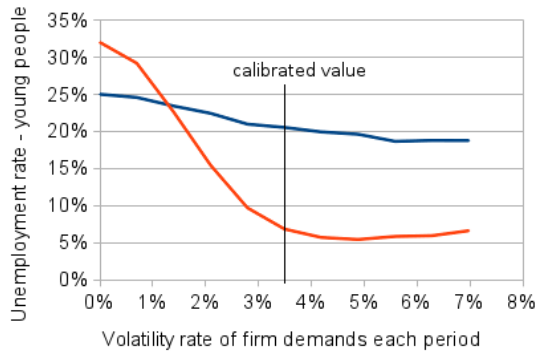

d) Global unemployment rate

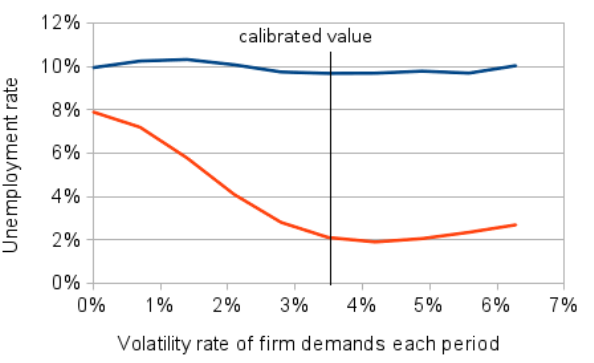

Fig. 5 Sensitivity to volatility of firm demands with and without FDC

job, mainly an FDC, which increases their experience and raises the probability to access an OEC later.

This highlights the existence of a positive stepping stone effect when FDC are allowed and volatility is low, which does not occur when only OEC exist. The degree of volatility of demand determines two opposed scenarios of the effects of FDC suppression. When volatility is low, the stepping stone effect overcomes the churning effect ${ }^{8}$. When the volatility is high the stepping stone effect disappears and there remains only a churning effect, which moreover is strengthened. At the level of the global unemployment rate, the reversal of hierarchy does not appear since the stepping stone is not so important for the older workers ( figure 5-d ).

\section{Discussion}

To sum up the WorkSim Model enables us to study different mechanisms that are at the core of the labor market policy experiment and produce opposed effects on unemployment, mainly the churning and the stepping stone effect. In the base sim-

${ }^{8}$ This is the case studied by Ballot [2,3], in which the firms represented sectors, which have a lower demand volatility than individual real firms 
ulation, which corresponds to the calibrated values for the French labor market in 2011 , with a relatively high volatility of idiosyncratic firm demand and employee turnover, the churning effect overcomes the stepping stone effect and the net effect of the suppression of FDC is an important decrease in unemployment. If the volatility of demand is very low, the turnover is also low, vacant jobs are very few, and the suppression of FDC makes the integration of young people and unemployed very difficult. The global unemployment rate remains lower but the unemployment rate for young people is higher.

The net effect of the FDC suppression may also be influenced by the buffer stock effect that we do not endogenize completely, because the firm decision to decide between an OEC and FDC is partly exogenous : first an OEC or FDC is drawn from a exogenous probability (calibrated) but then the firm decides to actually create the job following an endogenous decision process. However this buffer stock effect might not be very important, as some theoretical work suggest [5], and also because the French legal framework modeled in WorkSim allows to terminate an OEC during the trial period and to fire employees with less than one year without severance payment.

An extension of the study would consider some other firing costs such as the bargaining of supra legal severance payments, the necessity of obtaining authorization for collective economic layoffs and finally the reputation cost that can be incurred when laying off. Finally, we will improve the choice mechanism between OEC and FDC, so the firm will perform it in a endogenous way.

\section{References}

1. A. Auger and N. Hansen. Addressing numerical black-box optimization : CMAE-ES. LION 6, January 16-20, PAris, France, 2012.

2. G. Ballot. Marché du travail et dynamique de la répartition des revenus salariaux. Thèse pour le doctorat d'Etat d'Economie, Université Paris X-Nanterre, 1981.

3. G. Ballot. Modeling the labor market as an evolving institution: model artemis. Journal of Economic Behavior and Organization, 49(1):51-77, 2002.

4. S. Bentolila and G. Bertola. Firing costs and labour demand: how bad is eurosclerosis? The Review of Economic Studies, 57(3):381-402, 1990.

5. S. Bentolila, P. Cahuc, J. J. Dolado, and T. Le Barbanchon. Two-tier labor markets in the great recession: France vs. spain. Technical report, Discussion paper series//Forschungsinstitut zur Zukunft der Arbeit, 2010.

6. K. Berche, C. Hagneré, and M. Vong. Les déclarations d'embauche entre 2000 et 2010 : une évolution marquée par la progression des CDD de moins d'un mois. Acoss Stat, (143), December 2011.

7. C. Berson and N. Ferrari. Réduire la segmentation du marché du travail par des incitations financières ? DG Trésor 2013/04, DG Trésor, October 2013.

8. O. Blanchard and A. Landier. The perverse effects of partial labour market reform: fixed-term contracts in france. The Economic Journal, 112(480):F214-F244, 2002.

9. A. L. Booth, M. Francesconi, and J. Frank. Temporary jobs: stepping stones or dead ends? The economic journal, 112(480):F189-F213, 2002.

10. A. Bucher. Hiring practices, employment protection and temporary jobs. Paper 2010-13, TEPP Working Papers, 2010. 
11. COE. Emplois durablement vacants et difficultés de recrutement. Rapport du Conseil d'orientation pour l'emploi, page 28, 2013.

12. DARES. Les mouvements de main-d'oeuvre en 2011. DARES Analyses, (71), Octobre 2012.

13. C. De Froment. Pour une flexibilité responsable. Sociétal, (75):112-119, 2012.

14. R. Faccini. Reassessing labor market reforms: Temporary contracts as a screening device. Working paper, European University Institute, 2008.

15. N. Hansen and A. Ostermeier. Completely derandomized self-adaptation in evolution strategies. Evolutionary computation, 9(2):159-195, 2001.

16. INSEE. Population active à la recherche d'un autre emploi (PARAE). (87), octobre 2008.

17. INSEE. Entreprises selon le nombre de salariés et l'activité en 2011. 2011.

18. INSEE. Taux d'activité selon le sexe et la configuration familiale en 2011. 2011.

19. INSEE. Taux de chômage par âge en 2011. 2011.

20. INSEE. Une photographie du marché du travail en 2011. 2011.

21. INSEE. Fiches thématiques - Synthèse des actifs occupés - Emploi et salaires - Insee Références - Édition 2013. 2013.

22. INSEE. L'emploi dans la fonction publique en 2011. (1460), 2013.

23. Y. Jauneau and C. Nouel de Buzonniere. Transitions annuelles au sens du bit sur le marché du travail. INSEE, 2011.

24. D. Mortensen and C. Pissarides. Job creation and job destruction in the theory of unemployment. The review of economic studies, 61(3):397-415, 1994.

25. A. Omicini, A. Ricci, and M. Viroli. Artifacts in the A\&A meta-model for multi-agent systems. Autonomous Agents and Multi-Agent Systems, 17(3):432-456, December 2008.

26. E. Phelps. Microfoundations of employment and inflation theory. Macmillan, London, 1970.

27. B. Tito. Institutional reforms and dualism in european labor markets. Handbook of Labor Economics, 4:1173-1236, 2011. 